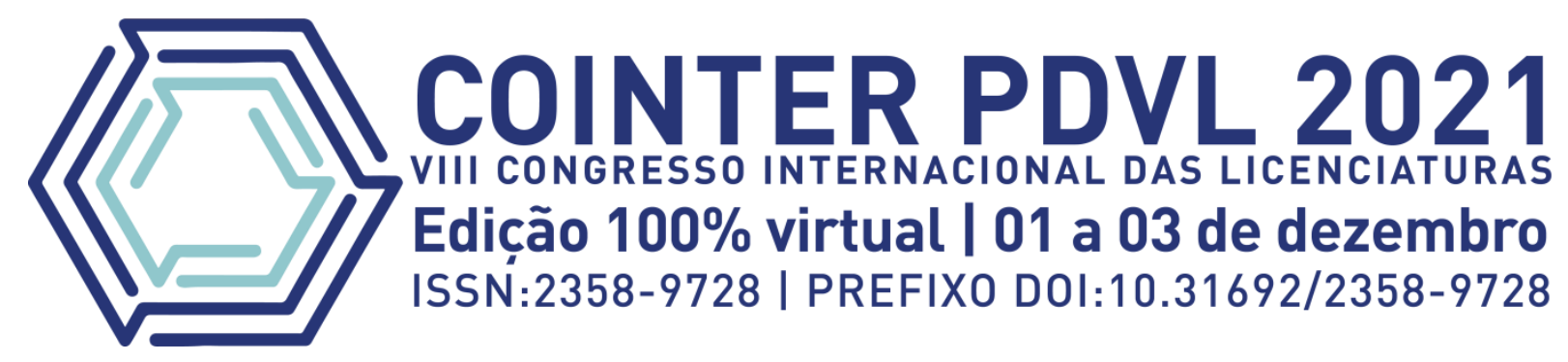

\title{
A IMPORTÂNCIA DA LUDICIDADE NO ENSINO DE BIOLOGIA: UM OLHAR ACERCA DA PRÁTICA DOCENTE E O PROCESSO DE APRENDIZAGEM ATRAVÉS DO PIBID
}

\section{LA IMPORTANCIA DE LA LUDICIDAD EN LA ENSEÑANZA DE LA BIOLOGÍA: UNA MIRADA A LA PRÁCTICA DOCENTE Y AL PROCESO DE APRENDIZAJE EN LA ESCUELA SECUNDARIA}

\section{THE IMPORTANCE OF LUDICITY IN BIOLOGY TEACHING: A LOOK AT TEACHING PRACTICE AND THE LEARNING PROCESS IN HIGH SHOOL}

\author{
Apresentação: Comunicação Oral \\ Cícera Vitória Marcelino Barros ${ }^{1}$; Wedson Francisco Silva Sales ${ }^{2}$; José Pinheiro do Monte ${ }^{3}$ Aretuza Ramos \\ Brito $^{4}$; Dan Vitor Vieira Braga ${ }^{5}$
}

DOI:https://doi.org/10.31692/2526-7701.VIIICOINTERPDVL.0276

\section{RESUMO}

As atividades lúdicas são importantes meios para a socialização do conhecimento. Dessa forma, os jogos educacionais podem ser utilizados com o objeto de transformação da linguagem científica, rica em termos precisos, porém, muito técnico para uma linguagem de fácil compreensão, além de permitir o desenvolvimento social, cultural e psicomotor dos estudantes. Os jogos podem aumentar a cognição, afeição, motivação e a criatividade dos aprendentes, sendo uma via eficiente que favorece o processo de ensino-aprendizagem.

O presente trabalho teve como objetivo conhecer alguns dos métodos de ensino aprendizagem através da utilização de atividades diferenciadas como jogos didáticos e brincadeiras que visem envolvar os conteúdos de Biologia e que incentivem a aquisição e compreensão dos assuntos abordados no decorrer das aulas para melhorar o desempenho dos estudantes, servindo ainda como auxílio aos docentes na realização do seu trabalho e na obtenção de resultados significativos. $\mathrm{O}$ estudo esteve voltado para o público do $2^{\circ}$ ano do ensino médio de uma escola Estadual de Referência no Sertão pernambucano, acerca das práticas biológicas, nos quais foram usados como auxílio para compreensão de conteúdos e fixação dos mesmos, tendo êxito nos quesitos trabalhados.

Diante disso, conclui-se este estudo obtendo resultados positivos quanto à importância da inserção do lúdico em aulas de Biologia, promovendo a afirmação deste como uma estratégia de ensino na procura de uma aprendizagem significativa e do prazer em aprender e ensinar. Este

\footnotetext{
${ }^{1}$ Licenciando em Ciências Biológicas, FACHUSC, cicera.barros@fachusc.com

${ }^{2}$ Licenciando em Ciências Biológicas, FACHUSC, wedson.sales@ fachusc.com

${ }^{3}$ Ciências Biológicas, FACHUSC, pinheirodumonte.@ hotmail.com

${ }^{4}$ Ciências Biológicas, FACHUSC, aretuza.ramos@ fachusc.com

${ }^{5}$ Mestre em Gestão e Políticas Ambientais, FACHUSC, dan.braga@fachusc.com
} 


\title{
A IMPORTÂNCIA DA LUDICIDADE NO ENSINO DE BIOLOGIA
}

processo mostrou também o quanto o jogo fascina e encanta os estudantes, sendo útil e significativo sua utilização para a aprendizagem, e podem ser usados para o desenvolvimento de habilidades e competências cognitivas trazendo benefícios tanto para a vida social e acadêmica.

Palavras Chave: Processo de ensino-aprendizagem, Ensino médio, Lúdico, Brincadeiras, Jogos.

\section{RESUMEN}

Las actividades lúdicas son medios importantes para la socialización del conocimiento. Así, los juegos educativos pueden utilizarse con el objeto de transformar el lenguaje científico, rico en términos precisos pero muy técnicos, en un lenguaje de fácil comprensión, además de permitir el desarrollo social, cultural y psicomotor de los estudiantes. Los juegos pueden incrementar la cognición, el afecto, la motivación y la creatividad de los educandos, siendo una forma eficaz que favorece el proceso de enseñanzaaprendizaje.

El presente trabajo tuvo como objetivo conocer algunos de los métodos de enseñanza y aprendizaje mediante el uso de diferentes actividades como juegos educativos y juegos que tienen como objetivo involucrar los contenidos de la Biología y que fomentan la adquisición y comprensión de las materias cubiertas durante las clases para mejorar la desempeño de los alumnos, estudiantes, sirviendo también de ayuda a los docentes en el desempeño de su trabajo y la obtención de resultados significativos. El estudio estuvo dirigido al público de segundo año de bachillerato de una Escuela Estatal de Referencia en el interior de Pernambuco, sobre prácticas biológicas, en las que se utilizaron como ayuda para la comprensión de los contenidos y su fijación, con éxito en la cuestiones abordadas.

Por tanto, este estudio concluye con resultados positivos en cuanto a la importancia de insertar actividades lúdicas en las clases de Biología, promoviendo su afirmación como estrategia de enseñanza en la búsqueda de aprendizajes significativos y placer en el aprendizaje y la enseñanza. Este proceso también mostró cómo el juego fascina y deleita a los estudiantes, siendo su uso útil y significativo para el aprendizaje, y puede ser utilizado para el desarrollo de habilidades y competencias cognitivas, trayendo beneficios tanto para la vida social como académica.

Palabras Clave: Proceso de enseñanza-aprendizaje, bachillerato, juego, juegos, juegos.

\begin{abstract}
Playful activities are important means for the socialization of knowledge. Thus, educational games can be used with the object of transforming the scientific language, rich in precise but very technical terms, into an easily understood language, in addition to allowing the social, cultural and psychomotor development of students. Games can increase learners' cognition, affection, motivation and creativity, being an efficient way that favors the teaching-learning process.

The present work aimed to know some of the teaching and learning methods through the use of different activities such as educational games and games that aim to involve the contents of Biology and that encourage the acquisition and understanding of the subjects covered during the classes to improve the performance of the students. students, also serving as an aid to teachers in carrying out their work and obtaining significant results. The study was aimed at the public of the 2 nd year of high school at a State School of Reference in the hinterland of Pernambuco, about biological practices, in which they were used as an aid to understanding the contents and fixing them, with success in the issues addressed.

Therefore, this study concludes with positive results regarding the importance of inserting playful activities in Biology classes, promoting its affirmation as a teaching strategy in the search for meaningful learning and pleasure in learning and teaching. This process also showed how the game fascinates and delights students, its use being useful and significant for learning, and can be used for the development of cognitive skills and competences, bringing benefits to both social and academic life.
\end{abstract}

Keywords: Teaching-learning process, high school, play, games, games.

INTRODUÇÃO 
No processo de educação deve-se ter como base a emancipação e autonomia plena do sujeito, tendo como garantia as diversas opiniões e a diversidade cultural, valores históricos e sociais (BRAGA, 2019). Entretanto, o desinteresse do professor quanto a didática utilizada ou do estudante em não compreender o seu papel em sala de aula, são as principais causas para o retrocesso do ensino de Biologia no ensino médio.

De acordo com Fialho (2013), o processo de aprendizagem envolve uma série de fatores distintos, como: a consciência, a memória e a emoção, e nesse contexto, os avanços tecnológicos e científicos servem como ponte para o conhecimento, estando os mesmos interligados ao ensino da Biologia. Porém, é notório que diversos conteúdos científicos são estudados de maneira superficial, mesmo possuindo uma grande relevância na vida do aluno.

Outrossim, o Programa Institucional de Bolsas de Iniciação à Docência (PIBID), é uma ação do Governo Federal que visa a valorização dos cursos de licenciatura. Nesse sentido, o mesmo promove a inserção dos licenciandos no ambiente escolar, onde vem a desenvolver em sua formação, atividades práticas criadas a partir da parceria entre autarquia e escolas estaduais (CAPES, 2019).

O Pibid prevê bolsas para estudantes de licenciatura que, orientados por professores universitários e da educação básica, participam de projetos na escola, a fỉm de possibilitar à aproximação da parte teórica dos cursos de graduação, com a prática nas salas de aula da rede pública de ensino. Além da aproximação do licenciando com a realidade da educação básica, o programa tem como objetivos: intensificar os diálogos entre a educação superior e a educação básica; qualificar a formação inicial de professores; fomentar práticas docentes e experiências metodológicas de caráter inovador, além de tornar a escola pública um espaço para reflexão e crescimento na construção do conhecimento (BRASIL, 2011).

Portanto, as atividades desenvolvidas pelos graduandos do Programa de Iniciação à Docência despertam interesse nos discentes do ensino médio, uma vez que acionam o desenvolvimento pessoal do aluno e o diferencial do professor, no qual, o lúdico promove motivação e estimula no processo de construção do conhecimento educativo. (SOARES, 2014).

Desse modo, este trabalho objetiva explicitar a importância da ludicidade no ensino de Biologia para alunos do ensino médio, trazendo consigo, práticas pedagógicas inovadoras, motivadoras e afetivas, das quais proporcionem ao estudante um melhor desenvolvimento em âmbito escolar e em meio social.

\section{FUNDAMENTAÇÃO TEÓRICA}

A atual educação exige uma drástica transformação no processo de ensino 


\title{
A IMPORTÂNCIA DA LUDICIDADE NO ENSINO DE BIOLOGIA
}

aprendizagem, pois, apesar das transformações nas áreas da ciência, o ensino de Biologia continua limitado (LUZ et al., 2018).

De acordo com Krasilchik (2004):

\begin{abstract}
Os problemas ligados a prática biológica no ensino médio, vão inerentemente de encontro com a falta de comunicação entre professor e aluno, uma vez que os estudantes perdem a oportunidade de interagir nas aulas, tendo em vista a falta de motivação no ambiente escolar (KRASILCHIK, 2004).
\end{abstract}

Como é sabido por todos, a aplicação da disciplina de Biologia no ensino médio passou por transformações que delinearam suas concepções e seus componentes curriculares, e nestas colocam o professor numa posição desafiadora onde o mesmo tem uma gama de conteúdos para transmitir da melhor maneira possível para que os alunos absorvam o que está sendo transmitido, portanto surge a necessidade de apresentar no ensino médio práticas inovadoras como a ludicidade, que vem crescendo a cada dia entre os educadores, só que nem sempre o ensino da disciplina fora assim, a mesma se restringia e padronizava apenas na teoria básica de ciências naturais através de aulas expositivas pelo professor e da aprendizagem mecânica do alunado. O professor deve considerar o conhecimento como um valor e não somente se preocupar com a eficácia de sua transmissão. É neste momento que ele precisa de lucidez para fazer as escolhas mais adequadas e acertadas (CORTELLA, 2009).

Contudo, o Pibid possibilita a vivênvia de práticas diferenciadas dentro do ambiente escolar, trabalhando o lúdico como ferramenta de auxílio para que o conhecimento chegue a cada estudante, ou seja, ferramentas básicas desenvolvidas em seu sentido literal, sendo o lúdico essencial para o desenvolvimento e aprendizado dos alunos que estão no processo de despertar e aprender ciências de forma descontraída (SILVA, 2011).

RAU(2011) ressalta que, as ferramentas lúdicas são recursos metodológicos como jogos e atividades que contribuem para o ensino e aprendizagem, contudo, tornam o ensino agradável tanto para os estudantes, quanto para os mestres. Nessa linha, Silva (2012) reafirma que "os profissionais da educação necessitam de capacitações e formações que propiciem uma nova dinâmica no cotidiano escolar, possibilitando aos docentes e discentes a interatividade com o conhecimento de forma objetiva e prazerosa". Com isso, as atribuições de Souza (2012) corroboram que, o lúdico é uma das primeiras formas que a criança encontra para o seu crescimento pessoal e social.

Ao analisarmos o contexto histórico e a trajetória da ludicidade vemos que as contribuições de vários estudiosos se fizeram essencial para o conceito que temos hoje, acerca 
das práticas do brincar não apenas na educação infantil, mas no ensino fundamental e no ensino médio. Vale destacar que a expressão "lúdica" está voltada à um conjunto de atividades que se usa para brincar e o mesmo é utilizado por educadores a levarem os educandos sejam eles crianças, jovens ou adultos a desenvolverem plenamente nos aspectos cognitivos e convívio social, na qual insere uma série de atividades, o caminho para tornar o aprendizado mais significativo é constituir uma prática pedagógica mais prazerosa, de maneira que torne a aprendizagem divertida (ALVES, 2009). Este fato é comprovado por inúmeros educadores e estudiosos, no qual desde os primórdios utilizam técnicas de jogos para divertimento como é o caso do futebol, dança e esportes em geral.

Salienta-se que a rede pública de ensino sofre com a defasagem de materiais e/ou equipamentos que poderiam ajudar no processo de ensino e aprendizagem dos estudantes, além de auxiliar os professores na diversificação de estratégias didáticas. Assim, é valido lembrar que nem todas as escolas possuem ambientes como labóratorios para aulas mais dinânicas, dessa forma as ferramentas ludicas surgem como um auxilio para o conhecimento, uma vez que as mesmas deixam as aulas mais expositivas (BEREZUK,2010)

De acordo com Kishimoto (1998), a ludicidade representa

[...] um primeiro nível do pensamento intuitivo, ainda nebuloso, mas que já aponta uma direção. O prazer e a motivação iniciam o processo de construção do conhecimento, que deve prosseguir com sua sistematização, sem a qual não se podem adquirir conceitos significativos.

Muitos profissionais da área educacional utilizam a ludicidade como um recurso pedagógico, pois a utilização de recursos lúdicos, como jogos e brincadeiras, auxilia a transposição dos conteúdos para o mundo do educando. Com isso, pode se afirmar que a ludicidade desenvolve um potencial cognitivo, motor e social aos estudantes. (ALMEIDA, 2008)

É importante considerar que a ludicidade, precisa antes de tudo ter um objetivo. Estes variam de acordo ao público alvo, mas no geral, precisam contribuir de maneira eficaz para a construção do conhecimento, estimular habilidades cognitivas aos alunos, levando-os a estabelecer relações mais abrangentes e criativas que facilitam a interiorização de certos conteúdos e o exercício da cidadania (KISHIMOTO, 1998).

De acordo com Ferreira (2019), a ludicidade no ensino de Ciências e Biologia também favorece o aperfeiçoamento e desenvolvimento de competências no professor, que tornarão as aulas mais dinâmicas, prazerosas e que contribuirão significativamente para a aquisição e construção de diversas habilidades e competências que os alunos precisam desenvolver. Além 


\section{A IMPORTÂNCIA DA LUDICIDADE NO ENSINO DE BIOLOGIA}

disso, a ludicidade estimula e provoca interações entre os estudantes, o que leva o adolescente à construção do conhecimento, uma vez que propicia o desbloqueio no pensamento e favorece a aprendizagem, pois brincando e/ou jogando os alunos conseguem acionar seus processos mentais elementares ou iniciais na construção do conhecimento que, com ajuda do professor, pode transforma-se em processos mentais mais elaborados (CABRERA, 2007).

Ademais, a utilização de jogos e aplicativos como ferramenta pedagógica tornam uma melhor interação entre professor e estudante, de maneira descontraída e agradável, tendo ainda, um maior rendimento, como também chances de possibilidades de permanência de cada aluno na escola. Desta forma, buscamos ressaltar a complementariedade das modalidades didáticas utilizadas pelos docentes, principalmente o complemento à aula expositiva. Nesse sentido, destacamos os jogos didáticos com uma possibilidade por possuir características que, associadas à intencionalidade do professor, podem promover momentos de aprendizados onde a diversão também se faz presente. (CONCEIÇÃO et al, 2020).

\section{METODOLOGIA}

Metodologia da pesquisa deve ser entendida como o conjunto detalhado e sequencial de métodos e técnicas a serem executados ao longo da pesquisa, de tal modo que se consiga atingir os objetivos inicialmente propostos. Para a conclusão deste artigo, descreveremos os procedimentos metodológicos utilizados, sendo assim, trataremos sobre como se procedeu a pesquisa que embasou a nossa análise.

A presente pesquisa foi realizada no município de Salgueiro-PE (Figura 01), localizado a 518 km da capital Recife, sendo desenvolvida na Escola de Referência em Ensino Médio de Salgueiro -EREMSAL, onde a mesma localiza-se as magens da BR-232 (Figura 2).

Figura 01: Mapa da cidade de Salgueiro-PE

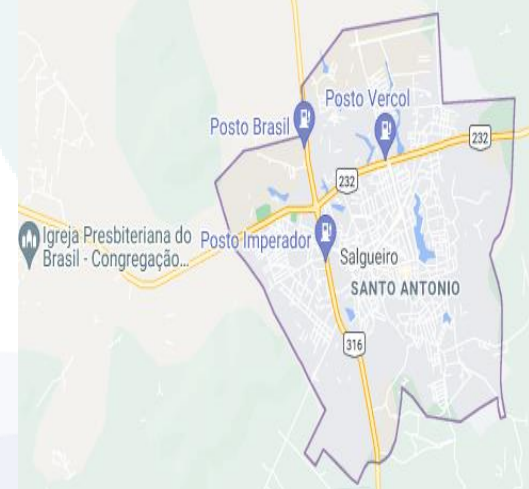

Fonte: Google maps(2021)

[6] 
Figura 02: Localização da escola EREMSAL.

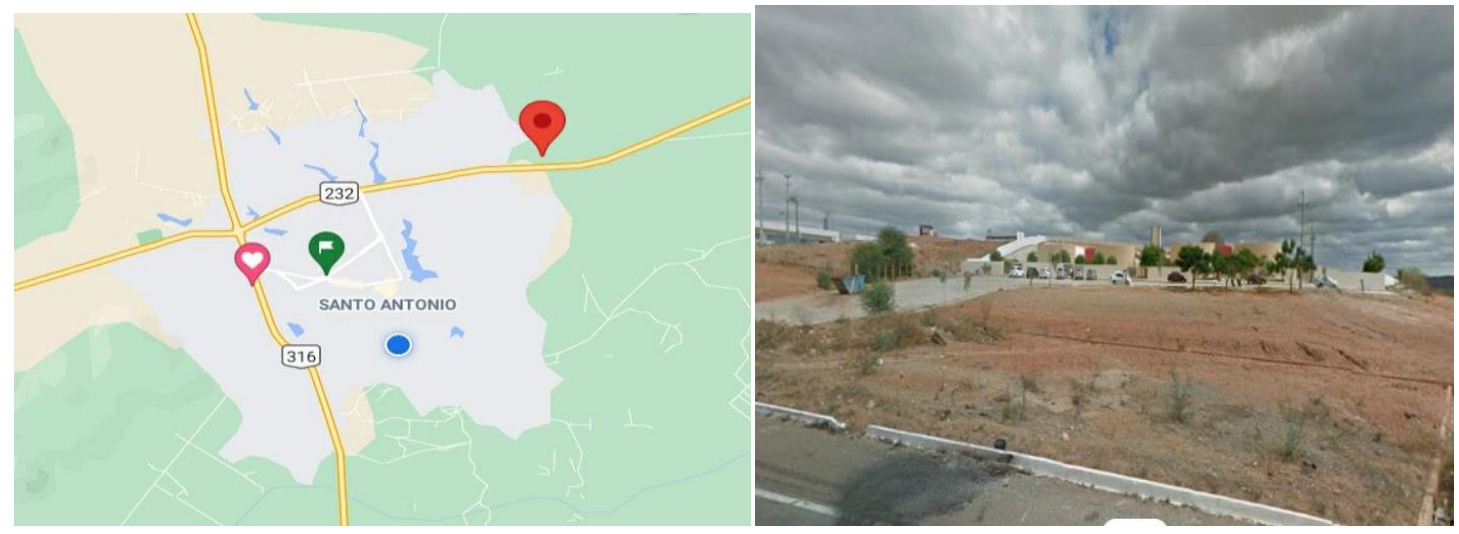

Fonte: Google maps(2021).

O referido trabalho é uma ação desenvolvida pelos bolsistas do Programa Institucional de Bolsas de Iniciação à Docência, da Faculdade de Ciências Humanas do Sertão Central, e foi desenvolvido no período de maio a setembro de 2021.

A proposta metodológica buscou base em duas etapas, a primeira contou com a observação e ambientação no contexto escolar, sendo a segunda a inserção nesse universo, que contou ainda com o desenvolvimento de práticas lúdicas na disciplina de Biologia no ensino médio.

Ademais, a presente pesquisa utilizou uma metodologia qualitativa e de exploração, pois buscou atingir métodos propostos dentro do conteúdo de biologia. Dessa forma, a primeira etapa situou os estagiários dentro das práticas pedagógicas desenvolvidas pelos professores e com base nas dificuldades encontradas dentro de sala de aula, introduziu-se o lúdico e visando refletir acerca de sua principal importância no desenvolvimento cognitivo dos estudantes.

A partir da observação do ambiente escolar, foram propostas e elaboradas ferramentas lúdicas a serem desenvolvidas junto ao professor de Biologia. Foram escolhidas turmas de $2^{\circ}$ ano do ensino médio que continham 20 estudantes cada turma, para desenvolvimento de tais ferramentas. Cabe salientar que essas atividades foram elaboradas diante de cada conteúdo, visto possíveis necessidades e dificuldades encontradas pelos educandos.

Através da vivência em sala de aula, notou-se dificuldades nos conteúdos de Morfologia Vegetal, Reino Fungi e Tecido Vegetais, tendo em vista esses problemas de compreenção da parte dos estudantes, os bolsistas desenvolveram ferramentas manuais e remotas, visando o pensamento de Tavares(2007), onde o mesmo afirma que ambientes multimídia podem propiciar situações que facilitam a construção de significados na aprendizagem dos estudantes, 


\section{A IMPORTÂNCIA DA LUDICIDADE NO ENSINO DE BIOLOGIA}

na medida em que oferecem, ao aprendiz, ferramentas poderosas, as quais o mesmo pode vir utilizar numa atividade individual e colaborativa. A atividade deu-se continuidade com aplicações de pré testes e pós testes visando avaliar o desempenho dos estudantes antes e depois da aplicação das ferramentas.

Buscando trabalhar de forma descontraida os conteúdos que os discentes apresentavam dificuldades, os Bolsistas de Iniciação a Docência fizeram a utilização do site Wordwall.com para a criação de jogos eletrônicos(Figura 04) e utilizaram materiais didáticos como: cartolina, cola e impreessões para a confecção de ferramentas multimídias(Figura 03).

A ferramenta que fora confeccionada a partir dos materiais didáticos como a cartolina, cola e etc, deu origem a um jogo de cartas que continha um sistema simples de perguntas e respostas, enquanto o jogo eletrônico buscava uma base mais lúdica que abordava feramentas multimídia, uma vez que se fazia presente no jogo artigos relacionados a linguagem verbal como textos e linguagem não verbal como imagens relacionadas ao conteúdo do Reino Fungi e emogis para facilitação da transmição do conteúdo(MAYER, 2001), onde a partir de uma roleta que ao ser girada, uma seta automática identificaria a pergunta ou prenda que o discente deveria pagar.

A utilização de imagens na confecção das ferramentas possuem significado bem mais aprofundado do que se espera. Através de imagens a transmição da informação virá em formato mais facilitador, uma vez que trabalhará não somento o lado conceitual, como também aboradrá em sua constituição a refleção e assimilação do conteúdo abordado(AMADOR, 1999).

Santos e Tarouco(2007) afirmam que a utilização de ferramentas verbais e não verbais em sala de aula ampliam diretamente a compreensão dos estudantes acerca do conteúdo trabalhado, uma vez que o discente terá a oportunidade de relacionar o conceitual com o coletivo.

Figura 03: Confeção de ferramenta multimídia acerca de Tecidos Vegetais e Morfologia Vegetal 


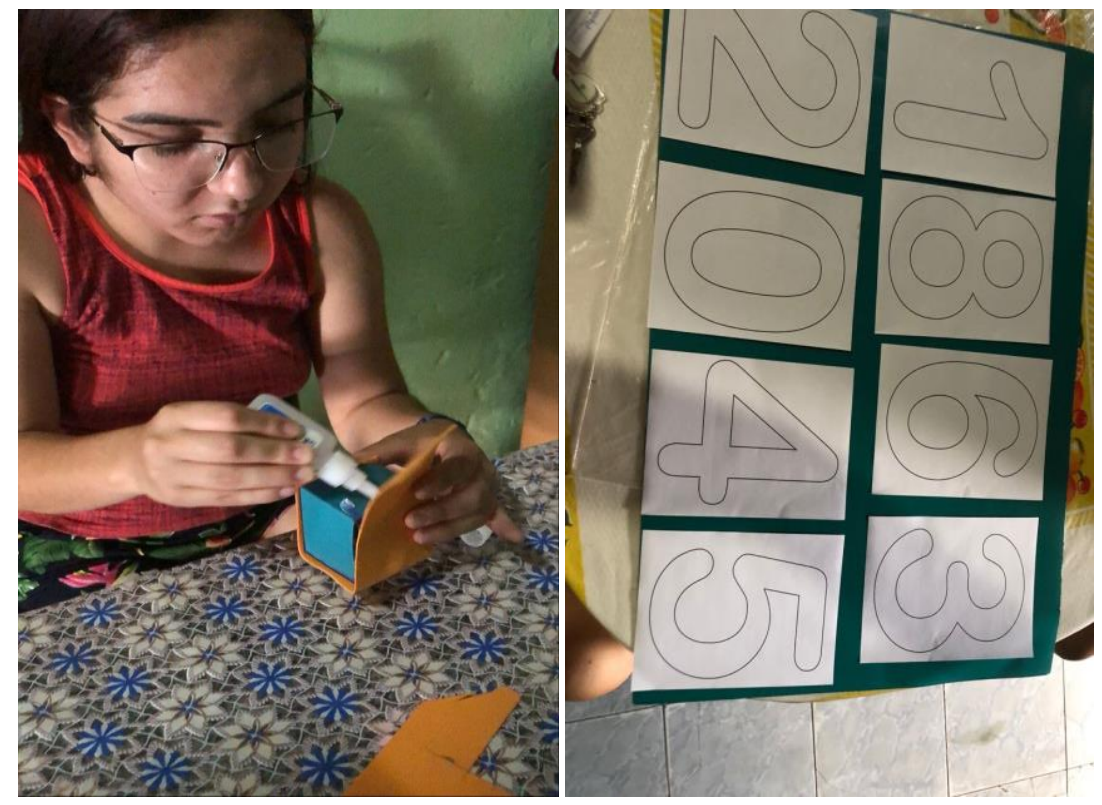

Fonte: Própria(2021)

Figura 04: Ferramenta digital acerca do Reino Fungi.

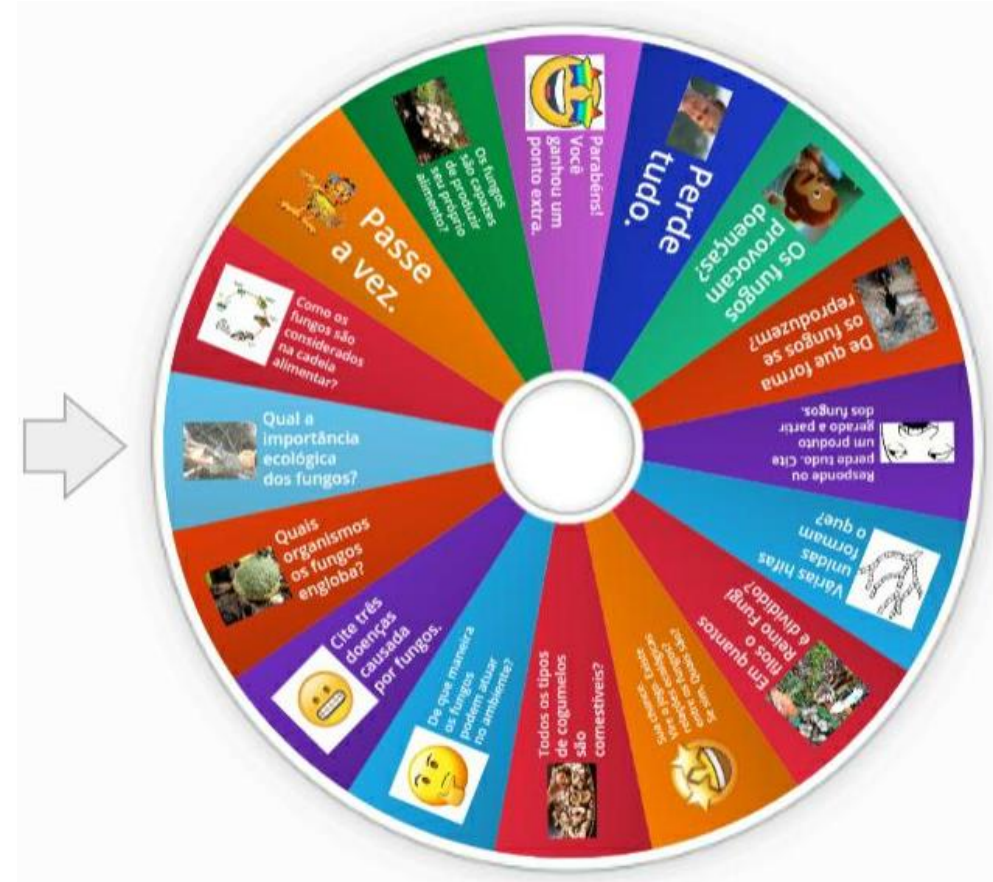

Fonte: Própria(2021)

\section{RESULTADOS E DISCUSSÃO}

Após o período de ambientação presenciado pelos estudantes de licenciatura, os mesmos passaram a observar as principais dificuldades enfrentadas pelo professor em sua metodologia de ensino. Aspectos como a participação dos educandos em algumas turmas onde eram lecionadas as aulas, foram identificados percebendo o quanto era uma tarefa difícil de se obter 


\section{A IMPORTÂNCIA DA LUDICIDADE NO ENSINO DE BIOLOGIA}

bons resultados.

Com essas observações, os pibidianos passaram a planejar atividades que gerassem resultados positivos para o ambiente escolar, como o planejamento e execução de ações lúdicas ligadas ao conteúdo trabalhado pelo professor naquela unidade letiva.

Primariamente foi planejado e executado ações que visassem averiguar o nível de aprendizagem dos estudantes acerca do conteúdo trabalhado pelo professor, o que resultou na aplicação de um pré teste para colher dados antes da aplicação da ferramenta e, posteriormente um pós teste que seria aplicado somente depois da ferramenta.

Após a aplicação do pré teste (Figura 05), notou-se que $60 \%$ da turma marcou corretamente as questões propostas no exame acerca dos Tecidos Vegetais e Morfologia Vegetal, o teste primário acerca do Reino Fungi teve uma avaliação de $67 \%$ de acertos, os demais deixaram as questões em branco ou marcaram as sentenças de forma incorreta.

Figura 05: Avaliação prévia de estudantes do $2^{\circ}$ ano do ensino médio na escola EREMSAL, Salgueiro-PE, através do pré-teste realizado.

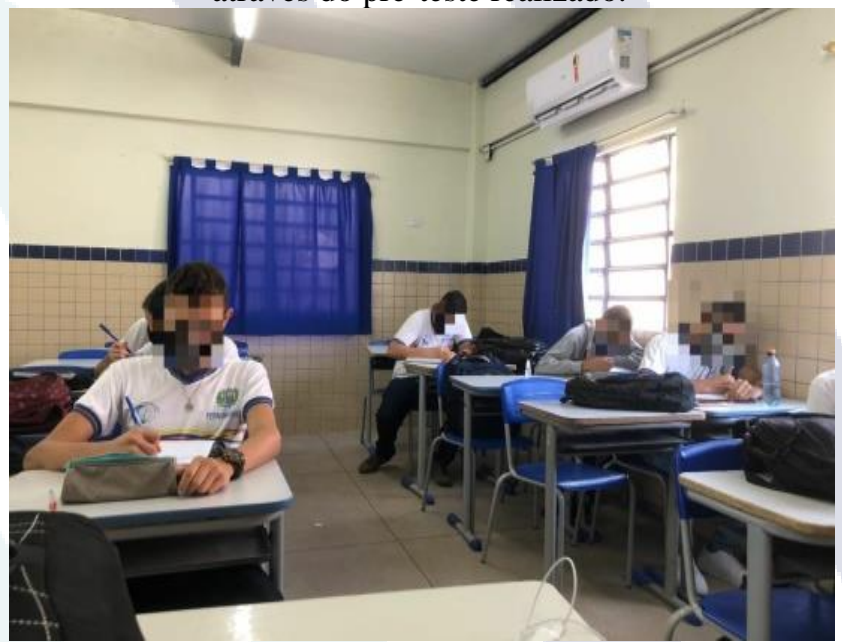

Fonte: Própria (2021)

Após o pré teste, os educandos foram direcionados pelos universitários ao pátio da escola para a aplicação da ferramenta manual (Figura 06) e posteriormente a apresentação da ferramenta eletrônica em sala de aula.

Os jogos tinham um sistema simples de perguntas e respostas que buscavam trabalhar a construção de uma aprendizagem significativa, uma vez que a aprendizagem significativa é um processo do qual o indivíduo relaciona uma nova informação com uma informação já existente no seu cognitivo, e desenvolve assim um meio mais efetivo de aprendizagem (AUSUBEL, 1998)

Sessa e Frateschi (2017) ressaltam a necessidade de ter uma educação científica que facilite uma visão metodologica e sistemática de ciência como uma das formas de compreender 
o unisverso, o que diretamente vem contribuindo na apropriação de uma aprendizagem ampla, que considere dimensões além de conhecer teorias científicas, ou seja, os contextos históricos, sociais e culturais que venham promover habilidades de desenvolvimento crítico.

Figura 06: O Jogo didático aplicado aos estudantes $2^{\circ}$ ano do ensino médio da escola EREMSAL, Salgueiro-

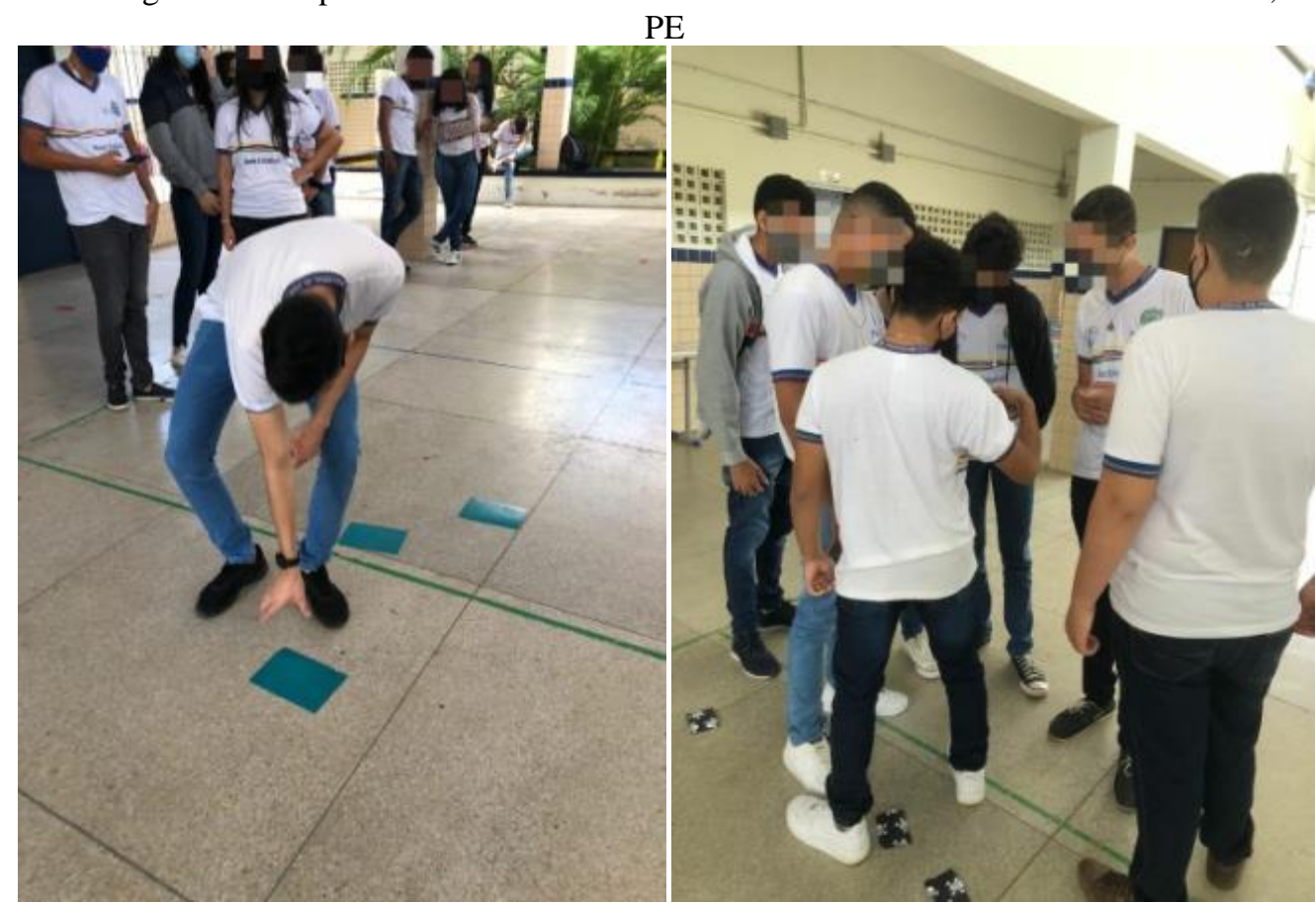

Fonte: Própria (2021).

Após a aplicação da ferramenta, os bolsistas aplicaram uma atividade para avaliar os dados movidos pela ação lúdica, o que resultou em um dado satisfatório para a equipe de universitários.

Os dados obtidos através dos pós testes revelaram que as ferramentas surtiram os efeitos esperados, sendo que houve um aumento crescente de $38 \%$ a mais de respostas corretas no jogo acerca dos Tecidos Vegetais e Morfologia Vegetal, o jogo eletrônico por sua vez, veio a ser aplicado em sala de aula como um instrumento inovador que trouxe consigo um resultado de $40 \%$ a mais de respostas respondidas corretamente.

Foi avaliado também a percepção dos discentes acerca das ferramentas aplicadas pelos bolsistas, o que gerou comentários como: "eu gostei da forma que os conteúdos foram trabalhados por vocês", ou "acredito que poderia aumentar as vezes que vão a nossa sala de aula.Seria muito bom ter mais brincadeiras desse tipo" o que gerou a participação ativa de todos da turma.

A eficácia óbvia desses instrumentos inovadores de ensino, destaca a eficiência dessa nova pedagogia, o que leva a reflexão sobre os benefícios trazidos pela prática de atividades 


\section{A IMPORTÂNCIA DA LUDICIDADE NO ENSINO DE BIOLOGIA}

lúdicas no ensino de Biologia, como aponta Ferreira (2019).

É importante considerar que a utilização de jogos pedagógicos integra o lúdico ao conteúdo, podendo potencializar o desejo de exploração e construção de um conhecimento, tornando possível por motivação interna típica da ferramenta lúdica, pois a função educativa do jogo é oportunizar a aprendizagem do indivíduo: seu saber, seu conhecimento e sua compreensão de mundo (ROLOFF, 2010).

\section{CONCLUSÕES}

Conclui-se que o lúdico no contexto dos jogos pedagógicos no ensino de Biologia torna uma aula mais agradável e dinâmica motivando os alunos a participarem ativamente da construção do próprio conhecimento trazendo mudanças significativas ao aluno.

O lúdico é uma das ferramentas de melhor apoio para ser desenvolvido em sala de aula, trazendo para o contexto de sala a importância do aprender brincando e com isso transmitindo o conhecimento.

Contudo, as escolas ainda precisam desfazer as dificuldades que existem em compreender este instrumento facilitador essencial na vida do educando, no entanto, muitas ainda priorizam o método tradicional de ensino, embora, os professores precisam ter consciência da importância das atividades lúdicas para o desenvolvimento e do processo de ensino aprendizagem.

\section{REFERÊNCIAS}

ALMEIDA, Paulo Nunes de. Educação lúdica: técnicas e jogos pedagógicos. São Paulo, SP: Loyola, 2008.

AUSUBEL, David P. A aprendizagem significativa. São Paulo: Moraes, 1982.

ALVES, E. M. S. A ludicidade e o ensino de matemática. 4. ed. Campinas: Papirus, 2009.

AMADOR, F.; CARNEIRO, M. H. O papel das imagens nos manuais escolares de ciências naturais do ensino básico: uma análise do conceito de evolução. Revista de Educação, Lisboa, v. 8, n. 2, p. 119-129, 1999.

BRASIL. Coordenação de Aperfeiçoamento de Pessoal de Nível Superior. Edital $\mathbf{n}^{\mathbf{0}} \mathbf{1}$ do Programa Institucional de Bolsa de Iniciação à Docência de 2011.

BRAGA, L. A relação entre a educação do campo e a educação popular: elementos de autonomia e emancipação humana. 2019 
BEREZUK, P. A; INADA, P. Avaliação dos laboratórios de ciências e biologia das escolas públicas e particulares de Maringá, Estado do Paraná. Acta Scientiarum. Human and Social Sciences, v. 32, n. 2, p. 207-215, 2010.

CABRERA, W. B.A ludicidade para o ensino médio na disciplina de biologia: Contribuições ao processo de aprendizagem em conformidade com os pressupostos teóricos da Aprendizagem Significativa. 2007. Dissertação (Ensino de Ciências e Educação Matemática) - Universidade Estadual de Londrina, Londrina, 2007.

CORTELA, M.S.; LA TAILLE,Y. Nos labirintos da moral. Campinas/SP: Papirus 7 Mares, 2009.

DA CONCEIÇÃO, A. R; MOTA, M. D. A; BARGUIL, P. M. Jogos didáticos no ensino e na aprendizagem de Ciências e Biologia: concepções e práticas docentes. Research, Society and Development, v. 9, n. 5, p. e165953290-e165953290, 2020.

FIALHO, W. C. AS DIFICULDADES DE APRENDIZAGEM ENCONTRADAS POR ALUNOS NO ENSINO DE BIOLOGIA. Praxia - Revista on-line de Educação Física da UEG, v. 1, n. 1, p. 53-70, 20 fev. 2013.

FERREIRA, A. A. dos S. N.; SANTOS, C. B. dos. A Ludicidade no Ensino da Biologia. Id on Line Rev.Mult. Psic., 2019, vol.13, n.45, p. 847-861

KRASILCHIK, Myriam. Prática de Ensino de Biologia. $4^{a}$ ed. São Paulo: Editora da Universidade de São Paulo, 2004.

KISHIMOTO, T. M. (org.). O Brincar e suas Teorias. São Paulo: Pioneira, 1998.

LUZ, P. S. da; LIMA, J. F. de; AMORIM, T. V. Aulas práticas para o ensino de biologia: contribuições e limitações no ensino médio. Revista de Ensino de Biologia da SBEnBio, [S. l.], v. 11, n. 1, p. 36-54, 2018. DOI: 10.46667/renbio.v11i1.107. Disponível em: http://sbenbio.journals.com.br/index.php/sbenbio/article/view/107. Acesso em: 21 ago. 2021.

MAYER, R. Multimedia learning. New York: Cambridge University Press, 2001

RAU, M. C. T. D. A ludicidade na educação: uma atitude pedagógica. Curitiba: ibpex, v. 20, 2011.

ROLOFF, E. M. A importância do lúdico em sala de aula. X Semana de Letras, v. 70, p. 1-9, 2010.

SOUZA, P. C. (2012). O lúdico e o desenvolvimento infantil. Revista do NUPE (Núcleo de Pesquisas e Extensão) do DEDC I/UNEB. Universidade do Estado da Bahia. vol. 01. n. 01. 2012.

SANTOS, L. M. A.; TAROUCO, L. M. R. A importância do estudo da teoria da carga cognitiva em uma educação tecnológica. Novas Tecnologias na Educação, Porto Alegre, v. 5, n. 1, p. 111, jul. 2007

SOARES, M. C., LANES, K. G., LANES, D. V. C., LARA, S., COPETTI, J., FOLMER, V., 
PUNTEL, R. L. (2014). O ensino de ciências por meio da ludicidade: alternativas pedagógicas para uma prática interdisciplinar. Revista Ciências \& Ideias ISSN: 2176-1477, 5(1), 83-105.

SESSA, P; FRATESCHI, S. (2017). Interações dialógicas no ensino de Biologia: modos semióticos e o processo de construção de significados nas atividades de campo. Revista Electrónica de Enseñanza de las Ciencias Vol. 16, $\mathrm{N}^{\circ}$ 2, 173-195. Recuperado de http://reec.uvigo.es/volumenes/volumen16/REEC_16_2_1_ex1031.pdf

TAVARES, R. Aprendizagem significativa em um ambiente multimídia. Indivisa: Boletín de Estudios de Investigación, Monografía 8, Madrid, p. 551-561, 2007. 